Lavk

C

(1) UNAGGSAII

t:

in

a
RISUS - Journal on Innovation and Sustainability Volume 6, número 3 - 2015 ISSN: 2179-3565

Editor Científico: Arnoldo José de Hoyos Guevara Editora Assistente: Nara Pamplona Macedo Avaliação: Melhores práticas editoriais da ANPAD

\title{
Fontes Externas no Processo de Inovação Aberta: Fatores Potencializadores e Restritivos em Startups de Base Tecnológica
}

\author{
Kelly Carvalho Vieira, Valderí de Castro Alcântara, \\ José Willer do Prado, Paulo Henrique de Souza Bermejo \\ Universidade Federal de Lavras, Minas Gerais, Brasil \\ E-mail: kellycarvalho@posgrad.ufla.br, \\ valderi.alcantara@posgrad.ufla.br, jwprado@posgrad.ufla.br, \\ bermejo@dcc.ufla.br
}

\begin{abstract}
Resumo: Apesar do número crescente de pesquisas sobre inovação aberta (open innovation), os estudos sobre esse modelo de inovação nas startups ainda são incipientes, especialmente, no Brasil. Com isso, este artigo objetiva descrever e analisar os desafios da inovação aberta, em startups de base tecnológica, através dos fatores potencializadores e restritivos presentes na busca por fontes externas de conhecimento. A pesquisa qualitativa foi realizada através de método de múltiplos casos com duas startups. A análise de conteúdo foi composta por duas categorias centrais: i) Busca por Fontes Externas e ii) Motivação e Antecedentes. Os resultados indicam que o principal fator potencializador foi a universidade através da estrutura física e suporte na busca por fontes de financiamento e competências internas demandadas pelas startups. Por seu turno, os impedimentos legais e burocráticos de transferência e negociação com fontes externas, além do receio do compartilhamento de conhecimentos e experiências internas foram os principais fatores restritivos. Por fim, a pesquisa indica uma situação que não contempla plenamente o modelo teórico da inovação aberta em decorrência de especificidades das startups e de limitações estruturais, culturais e legais.
\end{abstract}

Palavras-chave: Inovação Aberta; Fontes Externas; Startups. 


\title{
External Sources in the process of Open Innovation: Reinforcing and Restrictive Factors in Tech Startups
}

\author{
Kelly Carvalho Vieira, Valderí de Castro Alcântara, \\ José Willer do Prado, Paulo Henrique de Souza Bermejo \\ Universidade Federal de Lavras, Minas Gerais, Brasil \\ E-mail: kellycarvalho@posgrad.ufla.br, \\ valderi.alcantara@posgrad.ufla.br, jwprado@posgrad.ufla.br, \\ bermejo@dcc.ufla.br
}

\begin{abstract}
Despite that research on open innovation keeps in growing, applications in Startups are still incipient, especially in Brazil. Thus, this paper aims to describe and analyze the challenges of open innovation in technology-based Startups, seeking reinforcing and restrictive factors involved for external sources of knowledge. The study considered two startups on which were considered two main categories: i) Search by external sources and ii) Motivation and Background. The results indicated that the main Reinforcing or Fostering factor was the support being given by a University infrastructure as well as the one regarding the search for sources of funding and internal competencies needed by Startups. In turn, there were legal and bureaucratic problems regarding transfer and negotiation with external sources, these in addition to the fear of sharing knowledge and inner experiences in the context of open innovation were the main restrictive factors. So it seems that there are serious limits in trying to apply the Open Innovation Model in the case of Startups in Brazil due to structural, cultural and legal limitations.
\end{abstract}

Keywords: Open Innovation, External sources, Startups 


\section{INTRODUÇÃO}

Apesar do número crescente de pesquisas sobre inovação aberta, os estudos sobre esse modelo de inovação nas pequenas, médias empresas e startups ainda são incipientes (Hossain, 2013; Spithoven, Vanhaverbeke, \& Roijakkers, 2013; Vieira, Alcântara, \& Bermejo, 2014). As pesquisas existentes têm destacado questões relacionadas à implementação da inovação aberta (Zeng, Xie, \& Tam, 2010) e que a maioria das pequenas empresas não tem capacidade de P\&D e, em consequência, esse modelo de inovação é até mais importante para essas empresas do que para as grandes (Benedetti \& Torkomian, 2009; Spithoven, Vanhaverbeke, \& Roijakkers, 2013). No entanto, existem diversas temáticas que permanecem inexploradas. Nesse sentido, Huizingh (2011) enfatiza a necessidade de estudar práticas particulares de inovação aberta e as influências do ambiente externo nesse processo (incentivos governamentais à inovação, contexto social e econômico, relacionamentos com as universidades e outros). Dessa forma, são questionamentos ainda abertos a relação entre inovação aberta e desempenho; quais os modelos de negócios são coerentes com a inovação aberta; se em um modelo de negócio a inovação fechada pode coexistir com a inovação aberta; quais os fatores institucionais que influenciam a adoção do modelo de inovação aberta e ainda questões referentes a propriedade intelectual e patentes (Gassman, Daiber, \& Enkel, 2011; Benedetti \& Torkomian, 2013; Vieira, Alcântara, \& Bermejo, 2014).

Uma das temáticas que tem recebido atenção limitada pela literatura no âmbito da inovação aberta em pequenas, médias empresas e startups é a busca por fontes externas de conhecimento. Como se constata em Enkel et al. (2009) e Minshall et al. (2010) essas empresas enfrentam dificuldades em encontrar fontes externas e inserir a inovação aberta em seus negócios. Alguns estudos tentaram responder como as fontes externas participam do processo de inovação tecnológica de empresas que adotam o modelo de inovação aberta (Gassman, Daiber, \& Enkel, 2011; Benedetti \& Torkomian, 2013), mesmo assim, existe uma maior necessidade de pesquisas empíricas sobre os desafios da inovação aberta nessas empresas, especialmente sobre os fatores potencializadores e restritivos presentes na busca por fontes externas de conhecimento (Benedetti \& Torkomian, 2009; Gassman, Daiber, \& Enkel, 2011; Huizingh, 2011; Vieira, Alcântara, \& Bermejo, 2014).

Benedetti e Torkomian (2013) buscaram verificar em grandes empresas situadas no Brasil como ocorre o processo de busca por fontes externas. Com a intenção de investigar os fatores potencializadores e restritivos do processo de busca por fontes externas em um contexto diferente, o presente trabalho foca startups de base tecnológica incubadas em uma universidade. Destaca-se, nesse escopo, que a inovação tem sido considerada elemento essencial para as startups e que a realização de estudos em inovação aberta na América do Sul é ainda escassa (Houssain, 2012; Vieira, Alcântara, \& Bermejo, 2014). Além de que, são desconhecidos quais são os fatores específicos dessas empresas (startups de base tecnológica) que potencializam ou restringem a adoção do modelo de inovação aberta.

Portanto, este estudo é realizado para responder o seguinte problema de pesquisa: quais são os fatores potencializadores e restritivos na busca por fontes externas na inovação aberta em startups de base tecnológica? Como objetivo geral busca-se descrever e analisar os desafios da inovação aberta, em startups de base tecnológica, através dos fatores potencializadores e restritivos presentes na busca por fontes externas de conhecimento. Adiante, conceitualmente 
startup de base tecnológica é "empresa cuja estratégia empresarial e de negócios é sustentada pela inovação e cuja base técnica de produção está sujeita a mudanças frequentes, advindas da concorrência centrada em esforços continuados de pesquisa e desenvolvimento tecnológico" (Finep, 2012, p. 1). Em termos de estruturação empresarial é considerada uma "quase-empresa" (Finep, 2012).

O presente estudo é organizado por esta introdução, seguido da conceituação e apresentação de pesquisas sobre inovação aberta e um panorama dos estudos dessa temática em pequenas, médias empresas e startups e das fontes externas no processo de inovação. $\mathrm{Na}$ sequência, é apresentada a metodologia da pesquisa destacando o modelo conceitual. Na parte seguinte a apresentação e análise dos dados. Por fim, as conclusões, limitações e recomendações para pesquisas futuras.

\section{QUADRO TEÓRICO}

\section{Do modelo fechado ao modelo de inovação aberta}

A inovação é essencial para que as empresas desenvolvam novos produtos, processos e configurações que possibilitem atingir novos mercados (Bueno \& Balestrin, 2012). Nesse contexto, os debates sobre inovação extrapolaram as fronteiras tradicionais da empresa em direção ao paradigma da inovação aberta (open innovation) na qual existe a presença de fluxos de conhecimentos entre as empresas e seus stakeholders (Chesbrough, 2003; Benedetti \& Torkomian, 2013). Com isso muda-se também o pensamento tradicional sobre inovação (Perkmann \& Walsh, 2007). O paradigma da inovação aberta assume que as empresas podem usar ideias e conhecimentos tanto internos quanto externos (Chesbrough, 2003). Com base na Figura 1, na inovação aberta, observa-se que existe interação intencional entre a organização e o ambiente externo (fluxo multidirecional).

Figura 1: Modelo de inovação aberta de Chesbrough.

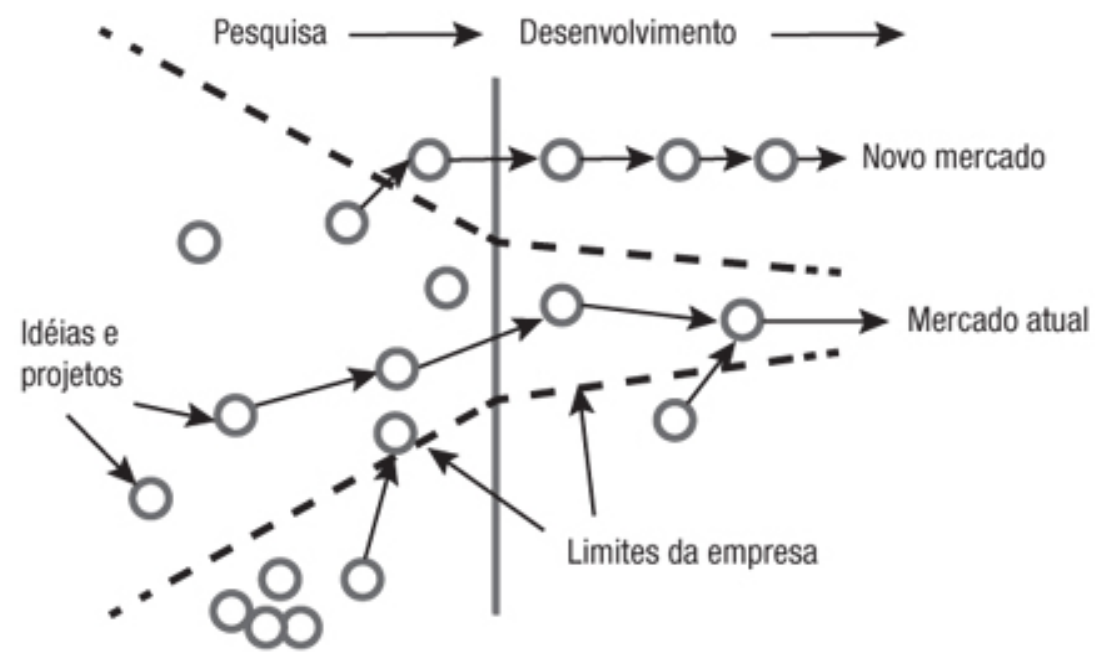

Fonte: Bueno \& Balestrin (2012, p. 520). 
O conceito de "inovação aberta" foi apresentado por Henry Chesbrough (2003) em contraposição ao modelo de "inovação fechada". Segundo o autor no modelo aberto o P\&D deixa de ser a única fonte de inovação e passa a ser fundamental a interação com fontes de conhecimentos externas. Especificamente, a utilização intencional de fluxos de entrada e saída de conhecimentos (Chesbrough \& Vanhaverbeke, 2006). Conceitualmente,

A inovação aberta consiste na utilização de fluxos de entrada e saída de conhecimento para a aceleração da inovação interna e expandir os mercados a partir do uso da inovação, respectivamente. A inovação aberta é um paradigma que assume que as empresas podem e devem usar ideias externas assim como ideias internas, caminhos internos e externos para o mercado, como olham para o avanço de suas tecnologias. A inovação aberta combina ideias internas e externas dentro de arquiteturas e sistemas, definidos por modelos de negócios que estabelecem mecanismos internos para se levar o valor gerado ao mercado externo. A inovação aberta assume também que as ideias internas podem chegar ao mercado por canais externos, fora dos negócios atuais da empresa, o que leva à geração de valor adicional (Benedetti \& Torkomian, 2009, p. 4).

Logo, a inovação aberta proporciona o compartilhamento de conhecimentos entre as organizações e com isso é possível construir novas tecnologias e criar novos mercados (Chesbrough, 2003; Abouzeedan \& Hedner, 2012; Benedetti \& Torkomian, 2013; Vieira, Alcântara, \& Bermejo, 2014). Nesse sentido, o Quadro 1 apresenta características ideais para os processos de inovação aberta no que tange a cultura, capacidades e motivação.7 
Quadro 1: Requisitos da inovação aberta

\begin{tabular}{|c|c|c|}
\hline Requisitos & $\begin{array}{l}\text { Desejável para a inovação } \\
\text { aberta }\end{array}$ & $\begin{array}{c}\text { Exemplo de mecanismos para o desenvolvimento de um } \\
\text { ambiente desejável }\end{array}$ \\
\hline Cultura & Cultura colaborativa e aberta. & $\begin{array}{l}\text { - Capacidades para o desenvolvimento de atividades e parcerias } \\
\text { colaborativas; } \\
\text { - } \quad \text { Atividades para a intensificação do trabalho em rede; } \\
\text { - vação aberta em programas de treinamento e desenvolvimento; } \\
\text { - Valorizar ideias/tecnologias obtidas externamente, em uma } \\
\text { tentativa de minimizar a síndrome do "não inventado aqui"; } \\
\text { - Suporte para a alta gerência administrativa. }\end{array}$ \\
\hline Capacidades & $\begin{array}{l}\text { Conjunto de habilidades } \\
\text { internas que permitem a } \\
\text { avaliação das capacidades, } \\
\text { bem como oportunidades } \\
\text { externas. }\end{array}$ & $\begin{array}{l}\text { - Os programas de treinamento e desenvolvimento que dão } \\
\text { suporte por habilidades técnicas e introspectivas (análise de } \\
\text { negócios internos), habilidades extrospectivas (análise externa) e } \\
\text { interativos (conexões internas e externas); } \\
\text { - Seleção de pessoas que possuem habilidades técnicas e in- } \\
\text { trospectivas, habilidades extrospectivas e também habilidades } \\
\text { interativas. } \\
\text { - Promoção da interação entre pessoas com diferentes habilida- } \\
\text { des; } \\
\text { Rotação de trabalho. }\end{array}$ \\
\hline Motivação & $\begin{array}{c}\text { Baixa resistência à introdução } \\
\text { da inovação aberta; Recom- } \\
\text { pensar quem apoia. }\end{array}$ & $\begin{array}{l}\text { - } \quad \text { Envolvimento de pessoas no processo de tomada de decisão; } \\
\text { - Melhoria dos processos de comunicação internos e externos; } \\
\text { - Sistemas de gratificação e planos de carreira com base em métri- } \\
\text { cas relacionadas resultados gerados pela inovação aberta. }\end{array}$ \\
\hline
\end{tabular}

Fonte: Adaptado e traduzido de Ades et al. (2013, p. 15).

Segundo Pitassi (2012) é preciso destacar que não existe um modelo de inovação aberta coerente com todas as organizações e que a efetividade da inovação aberta se relaciona com o ramo da organização, a sua cultura organizacional e seu modelo de negócio. Dessa forma, a passagem de um modelo de inovação fechada para o modelo da inovação aberta implica em mudança de mentalidade com relação à inovação (Perkmann \& Walsh, 2007; Benedetti \& Torkomian, 2013). Significa também deixar de lado uma parcela do controle do processo inovativo para acessar e utilizar ideias e conhecimentos externos (Chesbrough, 2003; Slowinski et al., 2009). Nesse sentido, diversas empresas abrem seus negócios e ampliam suas ligações com parceiros para serem capazes de ampliar seus produtos e a flexibilidade de produção (Munsch, 2009; Benedetti \& Torkomian, 2013). Segundo pesquisa realizada por Neyens, Faems e Sels (2010) o paradigma de inovação aberta enfatiza a importância das alianças para melhorar o desempenho inovador das empresas. Nessa direção, Savitskaya, Salmi \& Torkkeli (2010) destacam a importância da cooperação para a inovação aberta em estudo realizado na China e indicam também a importância da proteção dos direitos de propriedade intelectual. Contudo, nesse novo modelo de inovação um dos desafios é o estabelecimento de objetivos comuns (Chesbrough \& Schwartz, 2007; Benedetti \& Torkomian, 2013). 
Concomitantemente, a busca por conhecimento no paradigma da inovação aberta é fator determinante para que as empresas desenvolvam ou encontrem tecnologias específicas, as quais não conseguiriam desenvolver apenas internamente (Sandulli \& Chesbrough, 2009). Contudo, esse processo de busca precisa ser contínuo e fazer parte das rotinas de P\&D da organização (Perkmann \& Walsh, 2007). Segundo Sandulli e Chesbrough (2009) a inovação aberta consiste nas práticas de utilização do conhecimento e ao buscar fontes externas as empresas reduzem riscos e custos, bem como, aceleram os processos de inovação (Slowinski et al., 2009; Waguespack \& Fleming, 2009).

Finalmente, Huizingh (2011) enfatiza a necessidade de estudar práticas particulares de inovação aberta, as influências externas no processo e as relações com universidades, centros de pesquisas e outras empresas (Vieira, Alcântara, \& Bermejo, 2014). Dentro deste contexto destacam-se as possibilidades de pesquisas em pequenas e médias empresas (PMEs) e startups que têm recebido atenção limitada pela literatura (Narula, 2004; Waguespack \& Fleming, 2009; Neyens, Faems, \& Sels, 2010; Lee et al., 2010; Huizingh, 2011; Vieira, Alcântara, \& Bermejo, 2014).

\section{A inovação aberta em pequenas e médias empresas (PMEs) e startups}

Segundo Benedetti \& Torkomian (2013) a inovação aberta é mais estudada em grandes empresas, em parte, porque as pequenas e médias, bem como as startups, possuem menor capacidade de acessar recursos externos (Narula, 2004; Lee et al., 2010). No entanto, segundo Laursen e Salter (2004) essas organizações também possuem capacidade de inovação. Ademais, as pequenas empresas não dispõem de recursos, capacidade e proteção de propriedade intelectual, por isso, elas precisam colaborar estreitamente com outras pequenas e médias empresas (Parida, Westerberg, \& Frishammar, 2012). De acordo com os autores, essas empresas enfrentam o crescente número de atores no sistema de inovação, lidando com complexos desafios para a inovação e comercialização de suas tecnologias. Por essas razões, a inovação aberta nas PMEs e startups tornou-se crucial (Spithoven, Vanhaverbeke \& Roijakkers, 2013).

Entretanto, a inovação nas pequenas e médias empresas e startups tem recebido atenção limitada - estudos específicos sobre especialmente a inovação aberta não são comuns (Van de Vrande et al., 2009; Lee et al., 2010). As pesquisas existentes sobre inovação aberta concentramse principalmente em grandes empresas (Chesbrough, 2003; Benedetti \& Torkomian, 2013), mesmo sabendo que as contribuições das pequenas e médias empresas são extraordinariamente significativas em qualquer economia nacional e que a inovação aberta pode ser ainda mais importante para essas empresas do que para as grandes (Spithoven, Vanhaverbeke, \& Roijakkers, 2013).

Ademais, existem estudos sobre inovação aberta no contexto das pequenas e médias empresas realizados em empresas norte-americanas (Chesbrough, \& Crowther, 2006). No contexto europeu, algumas pesquisas empíricas com amostras maiores foram realizadas (Lichtenthaler, 2008; Van de Vrande et al., 2009; Parida et al., 2012). Alguns estudos também foram feitos em empresas da Ásia (Dejong \& Marsili, 2006; Kim \& Park, 2010; Lee et al., 2010; Massa \& Testa, 2008; Zeng et al., 2010; Suh \& Kim, 2012; Vrgovic et al., 2012). Embora existam alguns trabalhos sobre inovação aberta na América do Sul (Chaston \& Scott, 2012; Benedetti \& Torkomian, 2013; Vieira, Alcântara, \& Bermejo, 2014), nessa região, como pontua Houssain 
(2012) esse tema é praticamente inexplorado.

Em especial, esta pesquisa foca startups localizadas no Estado de Minas Gerais, Brasil. Por isso, é importante destacar que é muito comum que se confundam as definições de pequenas empresas e startups. Segundo Brigidi (2009) os proprietários de pequenas empresas diferem-se de empreendedores de startups no que diz respeito a capacidade de inovação, de julgamento, criação de demanda, vontade de crescimento, assim como habilidade gerencial. Em decorrência disso, as práticas de inovação aberta se tornam essenciais para estas organizações. Conforme Blank e Dorf (2012) o que diferencia uma startup de uma empresa comum é que as startups estão à procura de um plano de negócios, enquanto que empresas tem como núcleo central a execução de um plano de negócios conhecido. No caso das startups o plano de negócios é basicamente definido através de tentativas - até que se alcance um plano consistente e que possa gerar valor (Alberone, Carvalho, \& Kicorve, 2012).

Mesmo assim, alguns estudiosos conceituam startup como uma empresa recém-fundada ou com menos de dez anos (Hayton, 2002; Lussier, 1995). Para Salim et al. (2005, p. 13), startup "é aquela [empresa] que está sendo formada a partir da visão de um grupo de empreendedores, que se juntaram para concretizá-la”. Nesse sentido, para o Sebrae (2014) é um grupo de pessoas trabalhando com uma ideia diferente que pode ser lucrativa. Finalmente, por startup de base tecnológica entende-se aquelas que tenham na inovação tecnológica os fundamentos de sua estratégia competitiva: desenvolvendo produtos ou processos através de melhorias tecnológicas (Finep, 2012).

Relacionando ao escopo deste trabalho, Waguespack e Fleming (2009) defendem que as startups devem participar de comunidades de padrões abertos (práticas de inovação aberta). E, Chesbrough (2003) cita que o modelo de inovação aberta inclui empresas iniciantes. Além disso, Brigidi (2009) destaca a importância da inovação aberta para as startups de base tecnológica. Mesmo assim, "[...] poucos trabalhos têm relacionado inovação aberta e startups" (Souza \& Mello, 2013, p. 13).

Por fim, a inovação aberta pode potencializar o desenvolvimento das startups e possibilitar que suas inovações gerem valor (Vieira, Alcântara, \& Bermejo, 2014). Contudo, existem também fatores que restringem a inovação aberta nessas empresas, principalmente, no que tange a busca por fontes externas.

\section{Fontes externas no processo de inovação aberta}

É parte essencial do modelo de inovação aberta que a empresa fortaleça seus relacionamentos com institutos de pesquisa, universidades e outras empresas para ampliar a sua capacidade e desenvolver novos produtos e negócios (Slowinski et al., 2009). Outrossim, o uso de fontes externas no processo inovativo não é uma prática que se desenvolveu apenas com o paradigma da inovação aberta (Dosi, 1988; Freeman, 1991; Cohen, Wesley \& Levinthal, 1990).

No entanto, é importante destacar que na inovação fechada as ideias e projetos seguem um fluxo linear, do início ao fim do processo, e se concluídos, têm apenas uma saída na forma de um produto entregue ao mercado. Por outro lado, na inovação aberta como pontua Chesbrough (2003), os fluxos (externo e interno) devem ser propositais e atrelados a um modelo de negócios da empresa. Assim, para Costa e Maçada $(2011$, p. 7) as principais diferenças entre a inovação aberta e o paradigma convencional são: “a igual importância dada ao conhecimento externo, [...]; 
a centralização do modelo de negócio para converter P\&D em valor comercial; a saída intencional dos fluxos de conhecimento e tecnologia [e] o aumento dos intermediários da inovação [...]".

Segundo Benedetti e Torkomian (2013, p. 4) “a interação entre fabricante e usuário quanto a aquisição de novas tecnologias a partir de fornecedores ou de fontes pertencentes a outras cadeias produtivas" auxiliam na geração de novos produtos, processos ou negócios - destacando assim a importância das fontes externas. Ao abordar a criação e difusão de conhecimento entre os elos de uma rede, Cowan, Jonard e Zimmermann (2007) destacam dois pontos a serem considerados: em primeiro lugar, o valor de uma complementaridade cognitiva entre as partes, isto é, a habilidade em integrar seus respectivos conhecimentos; em segundo, o conhecimento criado em conjunto altera a posição de proprietário da firma individualmente e sua ligação com outras empresas no futuro. Como pontuam Benedetti e Torkomian (2013) fontes de informações externas em conjunto com a colaboração de usuários exercem importante papel no processo de criação de novos produtos.

Com foco em pequenas empresas, Vieira, Alcântara e Bermejo (2013) indicaram que as motivações para busca por fontes externas de conhecimento focam na existência de competências específicas e complementares. E também que existem diversos limites nos processos de compartilhamento de conhecimentos e experiências que se relacionam diretamente com a legislação brasileira. No entanto, existe uma maior necessidade de pesquisas empíricas para determinar o impacto dessas e outras características do contexto externo nas práticas de inovação aberta nestas organizações (Gassmann et al. 2011; Huizingh, 2011; Benedetti \& Torkomian, 2013; Vieira, Alcântara, \& Bermejo, 2014).

A seguir, é detalhado os procedimentos metodológicos utilizados para encontrar os fatores potencializadores e restritivos presentes na busca por fontes externas de conhecimento em startups de base tecnológica.

\section{PROCEDIMENTOS METODOLÓGICOS}

Neste trabalho, verificou-se que o tipo de pesquisa que se alinhava ao alcance dos objetivos propostos era a pesquisa exploratória. Esta pesquisa visa sanar algumas lacunas encontradas na literatura e pode trazer insights para estudos descritivos ou experimentais futuros (Vergara, 2000). Dessa forma, foi realizada uma revisão da literatura (que ajudou a construir o Quadro Teórico) e uma pesquisa de campo que permitisse captar e aprofundar o conhecimento a respeito da inovação aberta em startups.

Esta pesquisa buscou atingir com profundidade o tema abordado, além disso, foi realizada no campo com três startups, sendo assim caracterizada como um estudo de casos múltiplos (Vergara, 2000; Yin, 2005). Para selecionar as startups (localizadas no município de Lavras, Minas Gerais) que seriam as unidades deste trabalho, as orientações principais foram: a) Empresa (startups) de pequeno porte; b) Inovação como estratégia; c) Relação de colaboração com fontes externas. Além disso, as startups (duas) foram escolhidas pela disponibilidade em contribuir com este estudo. Outras duas foram contatadas, mas não houve disponibilidade em participar.

Os meios utilizados para coleta de dados foram: a entrevista em profundidade, a análise documental e a observação (Triviños, 1987; Godoy, 1995; Richardson, 1999; Yin, 2005). Concomitantemente, os dados foram coletados em duas startups que se enquadravam no perfil definido da amostra e concordaram em participar do estudo. Foram também feitas visitas com 
anotações de campo durante três meses.

Quatro entrevistas foram gravadas e posteriormente transcritas, e ainda, as startups disponibilizaram materiais (documentos) que também contribuíram para a construção da análise de conteúdo deste trabalho. O roteiro da entrevista focava nos processos de inovação aberta e os fatores relacionados a busca por fontes externas de conhecimento. Os entrevistados foram o diretor executivo da Startup A, neste trabalho chamado de Entrevistado A1 ( 25 minutos), e o diretor comercial identificado como Entrevistado A2 (36 minutos). Da Startup B foram entrevistadas a diretora executiva e uma sócia-pesquisadora, neste trabalho denominados: Entrevistada B1 (28 minutos) e Entrevistada B2 (26 minutos), respectivamente. Na pesquisa documental foram coletados dados em publicações internas e nos sites das startups. Na observação foram analisados espaços físicos, artefatos e comportamentos dentro das startups seguindo metodologia utilizada por Benedetti e Torkomian (2013). Uma das startups está localizada na incubadora de empresas de base tecnológica de uma universidade federal e a outra localizada dentro de um pólo tecnológico nas dependências da mesma universidade.

Os métodos e técnicas utilizadas, conforme já afirmado, foram baseados no trabalho de Benedetti e Torkomian (2013). Dessa forma, foi possível comparar os resultados desses autores (grandes empresas) com os fatores potencializadores e restritivos na busca por fontes externas em startups de base tecnológica. Ademais, a utilização de três fontes de dados possibilitou cruzar informações e obter uma análise mais aprofundada, conforme sugere o estudo de caso (Godoy, 1995; Richardson, 1999; Yin, 2005). Para auxiliar no processo de organização e análise dos dados foi utilizado o software NVivo 10 que permite reunir, organizar e analisar conteúdos de entrevistas.

Para a análise dos dados utilizou-se da análise de conteúdo (Bardin, 2004). As informações coletadas (entrevistas, observação e documentos) foram alocadas em diversas categorias e subcategorias, algumas definidas por Benedetti e Torkomian (2013) e outras acrescentadas por Vieira, Alcântara e Bermejo (2014). Dessa forma, as categorias definidas foram: "Busca por Fontes Externas" e "Motivação e Antecedentes". Adiante, cada categoria foi dividida em subcategorias específicas. No subtópico seguinte é apresentado este modelo conceitual.

\section{Modelo conceitual de investigação}

GO modelo para investigação dos fatores potencializadores e restritivos presentes na busca por fontes externas de conhecimento aqui utilizado foi proposto originalmente por Benedetti e Torkomian (2013) e posteriormente utilizado em pesquisa empírica e adaptado por Vieira, Alcântara e Bermejo (2014). O modelo apresenta duas categorias e sete subcategorias (Quadro 2). Destaca-se que através do modelo é possível ter acesso aos desafios da inovação aberta em startups de base tecnológica por meio dos fatores potencializadores e restritivos presentes na busca por fontes externas de conhecimento presentes em cada subcategoria. 
Quadro 2: Categorias de análise

\begin{tabular}{|c|c|c|}
\hline Categoria & Subcategoria & Descrição da categoria \\
\hline \multirow[t]{3}{*}{$\begin{array}{l}\text { Busca por Fontes } \\
\text { Externas }\end{array}$} & $\begin{array}{l}\text { Fortalecimento através } \\
\text { de Parcerias }\end{array}$ & $\begin{array}{l}\text { A relação de cooperação se fortalece ao longo do tempo e atrai outras } \\
\text { empresas e pesquisadores. }\end{array}$ \\
\hline & $\begin{array}{l}\text { Aquisição de Tecnolo- } \\
\text { gia Pronta }\end{array}$ & $\begin{array}{l}\text { Fusões e aquisições de outras empresas que já possuem expertise em } \\
\text { determinadas tecnologias constitui uma prática para adquirir tecnologia } \\
\text { e diminui a dependência de fornecedores. }\end{array}$ \\
\hline & $\begin{array}{l}\text { Busca por Fontes Exter- } \\
\text { nas de Financiamento }\end{array}$ & $\begin{array}{c}\text { Busca por recursos para realização dos processos de inovação. Pode ser } \\
\text { com entidades privadas ou públicas através de editais de incentivo a } \\
\text { ciência e tecnologia. }\end{array}$ \\
\hline \multirow[t]{4}{*}{$\begin{array}{l}\text { Motivação e } \\
\text { Antecedentes }\end{array}$} & $\begin{array}{l}\text { Necessidades Especí- } \\
\quad \text { ficas }\end{array}$ & $\begin{array}{l}\text { Necessidades que as empresas não são capazes de atender apenas com } \\
\text { suas competências internas. Análise da melhor opção entre desenvolver } \\
\text { internamente uma tecnologia ou recorrer a uma fonte externa. }\end{array}$ \\
\hline & $\begin{array}{l}\text { Competências Comple- } \\
\text { mentares }\end{array}$ & $\begin{array}{l}\text { Se refere a contratações de profissionais que participam do projeto ou } \\
\text { aquisição de empresas que já possuem a competência necessária. A } \\
\text { procura por fontes externas evita custos de desenvolvimento de infraes- } \\
\text { trutura e de pessoal e aceleração do processo de inovação e dos prazos } \\
\text { de execução. }\end{array}$ \\
\hline & $\begin{array}{l}\text { Compartilhamento } \\
\text { de Conhecimentos e } \\
\text { Experiências }\end{array}$ & $\begin{array}{l}\text { Trocas que ocorrem entre empresas, mesmo entre concorrentes, podem } \\
\text { ser vistas como ações estratégicas para aumento da competitividade. }\end{array}$ \\
\hline & $\begin{array}{l}\text { Licenciamento e } \\
\text { Comercialização de } \\
\text { Tecnologias }\end{array}$ & $\begin{array}{l}\text { Opção para obtenção de ganhos com tecnologias que não se alinham } \\
\text { aos modelos de negócios das empresas e que a literatura aponta como } \\
\text { característica importante no modelo aberto. }\end{array}$ \\
\hline
\end{tabular}

Fonte: Adaptado de Benedetti e Torkomian (2013) e Vieira, Alcântara e Bermejo (2014).

Na categoria 'Busca por Fontes Externas' é descrito como acontece o fortalecimento das empresas através do contato com os parceiros; como acontecem os processos para aquisição de tecnologias prontas e como ocorre a busca por fontes externas de financiamento. $O$ objetivo desta categoria é verificar se a busca por fontes externas ocorre de modo planejado, se é incorporada ao processo inovativo e se é formalizada por meio de acordos estabelecidos para que não haja dúvidas ou conflitos posteriores. E ainda, identificar se o fluxo de conhecimento ocorre tanto no sentido de entrada, ou seja, absorção do conhecimento externo pela empresa, quanto no sentido de saída, de forma que se possibilite a circulação e difusão do conhecimento para os parceiros externos (Perkmann \& Walsh, 2007; Sandulli \& Chesbrough, 2009; Slowinski et al., 2009; Benedetti \& Torkomian, 2013; Vieira, Alcântara, \& Bermejo, 2014). Na categoria 'Motivação e Antecedentes' são apresentadas algumas necessidades específicas das empresas (startups no caso da presente pesquisa empírica), e ainda, como ocorre a aquisição por competências complementares, além de, como acontece o compartilhamento de conhecimento e experiências e, finalmente, como acontece o licenciamento e comercialização de tecnologias (Calligaris \& Torkomian, 2003; Broring \& Herzog, 2008; Benedetti \& Torkomian, 2013; Vieira, Alcântara, \& Bermejo, 2014). Dessa forma, em conjunto as duas categorias possibilitam identificar de forma organizada os fatores potencializadores e restritivos da inovação aberta em startups de base tecnológica 


\section{APRESENTAÇÃO E ANÁLISE DOS DADOS}

A seguir são apresentadas as características das startups A e B que foram escolhidas como unidades de estudo e posteriormentea análise das duas categoriase suas subcategorias, abordando de maneira integrada o que se obteve na análise documental, entrevista em profundidade e observação. Nesse sentido, buscando sempre identificar os fatores potencializadores e restritivos presentes na busca por fontes externas de conhecimento nessas organizações.

\section{Apresentações da Startup A e da Startup B}

A Startup A (pequena "empresa" de base tecnológica) fornece produtos inovadores para avaliação da qualidade e os parâmetros de sementes, grãos e plântulas. Criada em 2008 a partir da ideia de jovens empreendedores, a empresa se estabeleceu no mercado através de uma parceria com uma universidade federal do sul de Minas Gerais. Atualmente a empresa está localizada dentro do campus dessa universidade e conta com uma equipe multidisciplinar de profissionais qualificados (segundo documentos analisados e observação). Focada no segmento do agronegócio, a startup desenvolveu core business na busca por soluções para alguns dos atuais problemas do setor. A tecnologia desenvolvida pela startup gerou produtos que tem por objetivo otimizar os recursos humanos e materiais no processo de análise de sementes (segundo análise dos documentos).

A Startup B é atuante no desenvolvimento de produto biotecnológico inovador, na realização de ensaios experimentais, bem como na prestação de serviços em análises laboratoriais. Ela visa atender o mercado da indústria alimentícia e de agronegócio. Embora ainda recente (fundada em 2007), a empresa surgiu como resultado de mais de vinte anos de pesquisas desenvolvidas por seus idealizadores. Atualmente está situada em uma universidade federal do sul de Minas Gerais e conta com apoio de pesquisadores da própria universidade e de uma instituição de pesquisa do estado de Minas Gerais (segundo análise da observação e documentos). A Startup B possui segundo análise documental grande potencial de crescimento tendo em vista seu alinhamento com as demandas por sistemas produtivos sustentáveis, produtos seguros sob o ponto de vista de segurança alimentar e proteção do meio ambiente (informações disponível em site).

\section{A busca por fontes externas: fatores potencializadores e restritivos}

Antes propriamente de debater as categorias é apresentada na Figura 2 uma nuvem das palavras mais comuns nas entrevistas (extraído do software NVivo 10). Pela nuvem de palavras constata-se que nas entrevistas as palavras mais repetidas foram "tecnologia", "universidade", "transferência", "mercado" e "patente" (em destaque na nuvem). Constatamos que essas palavras são comuns no âmbito de trabalhos sobre startups e inovação aberta (Chesbrough, 2003; 2006; Waguespack \& Fleming, 2009; Brigidi, 2009; Abouzeedan \& Hedner, 2012; Benedetti \& Torkomian, 2013; Hossain, 2013; Spithoven, Vanhaverbeke, \& Roijakkers, 2013; Souza \& Mello, 2013; Vieira, Alcântara, \& Bermejo, 2014). 
Figura 2: Nuvem de palavras das entrevistas.

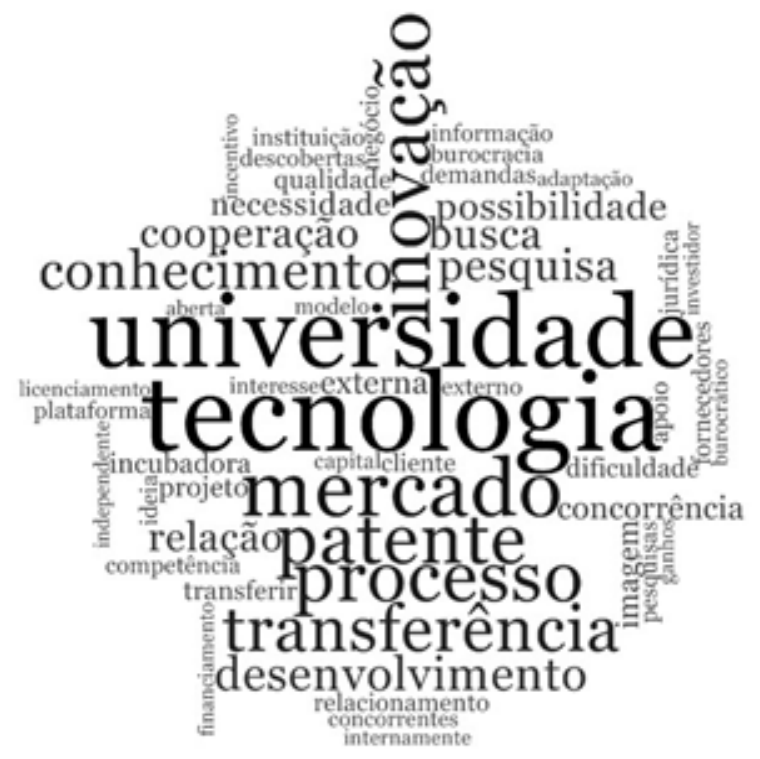

Fonte: Elaborado através do software NVivo 10 for Windows.

Essas palavras possuem forte relação com o processo de inovação aberta e fazem parte do cotidiano nas startups. A tecnologia é pontuada pelos entrevistados no contexto da captura de conhecimento de fontes externas de outras organizações, o que como pontua Witzeman et al. (2006), constitui-se um fato comum no processo inovativo. A universidade teve destaque, ela é citada entre as entrevistas por permitir que as startups busquem superar e resolver problemas e dificuldades pontuais e estruturais (as startups estão incubadas em uma universidade). Citada pelos entrevistados como uma estratégia de geração de valor, a patente, também possui lugar de destaque na nuvem e está diretamente ligada ao processo inovativo. Nesse escopo, a palavra transferência pode ser considerada o elemento de ligação entre as demais e o mercado (Chesbrough, 2003; 2006).

\subsection{Categoria 1: Busca por Fontes Externas}

A busca por fontes externas de conhecimento foi analisada a partir dos critérios apresentados no modelo conceitual: Fortalecimento através de parcerias, Aquisição de tecnologia pronta e Busca por fontes externas de financiamento. O Quadro 3 apresenta os principais relatos. 
Quadro 3: Categoria 'Busca por Fontes Externas' - relatos das entrevistas

\begin{tabular}{|c|c|c|}
\hline Subcategoria & Relato & Entrevistas \\
\hline \multirow[t]{4}{*}{$\begin{array}{l}\text { Fortalecimento através de } \\
\text { parcerias }\end{array}$} & \multirow[t]{2}{*}{ Relato 1} & $\begin{array}{c}\text { Entrevistado A1: A incubadora cede o local [...] conseguimos ter um } \\
\text { aumento gradativo de espaço aqui dentro [...] nós temos a redução de } \\
\text { custos operacionais. }\end{array}$ \\
\hline & & $\begin{array}{l}\text { Entrevistada B1: [...] então, hoje esse subsídio que a universidade nos } \\
\text { dá, dessa parceria, é [...] é o que tá nos mantendo no mercado. }\end{array}$ \\
\hline & \multirow[t]{2}{*}{ Relato 2} & $\begin{array}{l}\text { Entrevistado A2: Uma coisa que [...] nos auxilia é a busca por mão de } \\
\text { obra [...] e tem o respaldo da universidade como nome que ajuda no } \\
\text { mercado também, como posicionamento de empresa. }\end{array}$ \\
\hline & & $\begin{array}{l}\text { Entrevistada B1: Vem sendo desenvolvido em parceria de pesquisado- } \\
\text { res da [instituição de pesquisa agrícola] com professores da univer- } \\
\text { sidade na área de desenvolvimento, pesquisa e desenvolvimento de } \\
\text { bioprodutos. }\end{array}$ \\
\hline \multirow[t]{2}{*}{$\begin{array}{l}\text { Aquisição de tecnologia } \\
\text { pronta }\end{array}$} & \multirow[t]{2}{*}{ Relato 3} & $\begin{array}{l}\text { Entrevistada B2: Como são produtos de base tecnológica nós temos } \\
\text { sempre que optar por laboratórios que forneçam os melhores reagen- } \\
\text { tes, os equipamentos que forneçam maior precisão, então é com base } \\
\text { na qualidade. }\end{array}$ \\
\hline & & $\begin{array}{c}\text { Entrevistado A1: A gente identificou um novo motor, que é [...] um } \\
\text { pouco mais fraco, [...] e aparenta dar menos manutenção. A gente } \\
\text { adquiriu um, fez adaptação no equipamento pra funcionar [...] [referin- } \\
\text { do-se a um equipamento japonês]. Ver como ele funciona, pra tentar } \\
\text { colocar dentro da nossa máquina. [...] é uma tecnologia onde a gente } \\
\text { viu algo que pode servir. }\end{array}$ \\
\hline \multirow[t]{3}{*}{$\begin{array}{l}\text { Busca por fontes externas } \\
\text { de financiamento }\end{array}$} & \multirow[t]{2}{*}{ Relato 4} & $\begin{array}{l}\text { Entrevistado A1: A parte de fomento, nós usamos bastante, procu- } \\
\text { ramos submeter projetos em todos os editais [projetos através da } \\
\text { universidade]. Então, em termos de recursos, [...] nesses quatro anos } \\
\text { de vida que a empresa tem [...] foi sustentada por causa disso. }\end{array}$ \\
\hline & & $\begin{array}{l}\text { Entrevistada B2: Hoje a gente tem buscado [...] programas, projetos } \\
\text { do governo, que está havendo muito incentivo nesse sentido. Então a } \\
\text { gente tem buscado esses caminhos pra poder sustentar, hoje a gente } \\
\text { não tem uma empresa, sustentável, a gente vive de projeto. }\end{array}$ \\
\hline & Relato 5 & $\begin{array}{l}\text { Entrevistado A2: Em termos de anjo ou venture capital [...] algumas } \\
\text { delas já vieram sondar a gente, mas, o modelo de negócio deles não } \\
\text { nos atraiu.[...] não estamos abrindo mão do nosso capital. }\end{array}$ \\
\hline
\end{tabular}

Fonte: Dados da pesquisa.

Na subcategoria Fortalecimento através de Parcerias, observou-se que o crescimento das startups teve como eixo central a inovação para entrada em novos mercados, o que foi resultado, de uma parceria com universidades e centros de pesquisa. Merece ser visto de forma especial os diversos benefícios que as startups recebem através dessas parcerias, sendo esse um fator potencializador a inovação aberta. Por estar incubada dentro da universidade é possível visualizar que as empresas utilizam a infraestrutura de P\&D da instituição. Conforme relatos dos entrevistados e documentos internos, elas têm o apoio nos processos de registro de patentes e exposição dos produtos em eventos promovidos pela universidade.

A parceria com a universidade permite que a empresa supere a dificuldade de encontrar pessoas com as competências certas para determinadas posições - fator que poderia prejudicar a competitividade no desenvolvimento de novas tecnologias (Relato 2). Além da parceria com 
as instituições de ensino e pesquisa, identificou-se que as startups também, de forma indireta, aumentam sua competitividade em decorrência da imagem institucional da universidade - fator que corrobora com os resultados de Benedetti e Torkomian (2013). Dessa forma, a parceria com a universidade permite que ambas as startups analisadas busquem superar e resolver problemas e dificuldades. Adiante, a relação de cooperação entre as empresas e a universidade confirmam as pontuações de Etzkowitz e Leydesdorff (1999): ela é fortalecida com a experiência ao longo do tempo e tem atraído outras empresas e pesquisadores, possibilitando aprendizado e acúmulo de conhecimento aos participantes.

Verificou-se na subcategoria Aquisição de Tecnologia Pronta a prática em adquirir tecnologias prontas. A Startup B realiza um monitoramento contínuo do ambiente externo, com o objetivo de localizar oportunidades potenciais como, por exemplo, a incorporação de uma tecnologia pronta aos seus produtos. Constatou-se, como pode ser verificado no Relato 3, que a busca por tecnologia é pautada na qualidade e o monitoramento é realizado com fornecedores e também com empresas concorrentes.

Nas grandes empresas a captura de conhecimento de fontes externas através de fusões e aquisições de outras empresas que já possuem expertise em determinadas tecnologias é fato comum (Witzeman et al., 2006). Consoante com essa característica das grandes empresas, as startups estudadas por se tratarem de "empresa" tecnológica detentora de algumas tecnologias inovadoras, já receberam algumas propostas de empresas interessadas na aquisição de suas tecnologias. No entanto, como observado nos relatos nas startups analisadas esse é um fator restritivo ao uso das estratégias de inovação aberta. As startups nem sempre acham vantajoso negociar suas tecnologias com outras empresas, além disso, possuem restrições em utilizar tecnologia pronta alegando não confiar no produto de outra empresa, o que se configura na "[...] síndrome do não-inventado-aqui, onde inovações e ideias são rejeitadas porque não foram criadas e desenvolvidas internamente" (Lorenzoni \& Baden-Fuller, 1995, p. 151).

Constatou-se na subcategoria Busca por Fontes Externas de Financiamento, a partir da análise documental, observação e entrevistas, que os projetos de financiamentos de pesquisas acadêmicas tem sido o passo inicial para o crescimento e expansão dessas empresas. Como pode ser identificado no Relato 4, as startups se mostraram adeptas a busca de fontes externas de financiamento. Em relação a investimentos no que tange ao capital de risco, verificou-se um comportamento distinto entre as duas startups estudadas. A Startup B se mostrou favorável a obtenção de financiamento através dessa modalidade, enquanto que a Startup A mostrou resistência, mas ainda assim utiliza-se desse meio de captação de recurso, conforme pode ser visto no Relato 5. Como pode ser observado um dos principais atores de um sistema de inovação é o entorno financeiro que se caracteriza pelas instituições provedoras de capital de risco, assumem parte do risco que permeia as atividades inovativas (Ballon \& Hawkins, 2009).

A falta de recursos financeiros é o problema mais frequentemente com relação aos processos de inovação principalmente em startups de base tecnológica. Como pode ser identificado no discurso dos entrevistados e até pela própria natureza das atividades a que essas startups se dedicam - introdução de tecnologias geralmente não testadas no mercado - o risco do investimento é frequentemente elevado (Pinho, Côrtes \&, Fernandes, 2002). Nesse aspecto, a Lei da Inovação prevê, que as agências de fomento devem promover, por meio de programas específicos, ações de estímulo à inovação nas micro e pequenas empresas, inclusive mediante 
extensão tecnológica (Lei n. 10.973, 2004). Nesse aspecto a legislação é um fator potencializador do uso da inovação aberta, pois assegura o tratamento favorecido a empresas inovativas.

Porém ainda no que diz respeito a legislação, há um fator restritivo ao uso do processo aberto de inovação e busca de fontes externas. As startups analisadas, por estarem incubadas em uma universidade, possui em seu quadro de sócios proprietários professores ou servidores da universidade. Embora a lei da inovação incentiva à participação de professores e pesquisadores nos projetos de invenção de tecnologia e P\&D, por se tratar de pequenas empresas fundadas por professores, esbarram no princípio da moralidade da Constituição Federal de 1988 (Constituição da República Federativa do Brasil, 1988/2001). Além disso, a Lei de Inovação que incentiva à pesquisa científica e tecnológica no ambiente produtivo, no contexto analisado, entra em conflito também com a Lei de Licitação (Lei n. 8.666, 1993). Os sócios proprietários, enquanto servidores da administração pública, não podem participar de processos licitatórios e, nem tão pouco, de contratos de compra e venda seja diretamente ou indiretamente com qualquer empresa independente se startup, pequena, média ou grande empresa. Aqui, encontra-se o principal fator restritivo da inovação aberta e da busca por fontes externas de conhecimento encontrado nas startups analisadas. Essa questão aparece também na categoria 'Motivação e Antecedentes'.

\subsection{Categoria 2: Motivação e Antecedentes}

A motivação e as experiências ou antecedentes que impulsionaram a empresa a utilizar o conhecimento que é produzido fora da organização são analisadas a partir dos critérios apresentados no modelo conceitual (Quadro 4). Através destas categorias serão debatidos os fatores potencializados e restringentes encontrados nesse processo. 
Quadro 4: Categoria 'Motivação e Antecedentes' - relatos das entrevistas

\begin{tabular}{|c|c|c|}
\hline Subcategoria & Relato & Entrevistas \\
\hline \multirow[t]{2}{*}{$\begin{array}{l}\text { Necessidades } \\
\text { específicas }\end{array}$} & Relato 6 & $\begin{array}{l}\text { Entrevistada B2: [...] o próprio produto que a gente produz hoje é fruto de uma infor- } \\
\text { mação extra da empresa. E isso acabou puxando várias demandas nossas. }\end{array}$ \\
\hline & Relato 7 & $\begin{array}{c}\text { Entrevistado A2: Nós já temos clientes [...] procurando uma parceria com a gente } \\
\text { para [...] desenvolver produtos específicos pra necessidade deles. Mas aí não é utili- } \\
\text { zando nossa competência, é criar produtos novos. Então, tá começando a [...] entrar } \\
\text { nesses [...] tipos de parcerias. }\end{array}$ \\
\hline \multirow[t]{3}{*}{$\begin{array}{l}\text { Competências } \\
\text { complementa- } \\
\text { res }\end{array}$} & Relato 8 & $\begin{array}{l}\text { Entrevistado A1: A gente vai ter que buscar alguma pessoa pra nos ajudar com essa } \\
\text { tecnologia que a gente não tem, não temos espaço, a gente não tem pessoa especia- } \\
\text { lizada. }\end{array}$ \\
\hline & & $\begin{array}{l}\text { Entrevistada B2: Às vezes alguns testes a gente tem que fazer em campo, então, nós } \\
\text { contamos com auxilio de [propriedades rurais]. }\end{array}$ \\
\hline & Relato 9 & $\begin{array}{l}\text { Entrevistado A2: A gente está querendo ganhar tempo. Com novas parcerias entran- } \\
\text { do aqui, a gente consegue fazer uma parte do desenvolvimento do hardware com } \\
\text { terceiros. }\end{array}$ \\
\hline $\begin{array}{l}\text { Comparti- } \\
\text { Ihamento de } \\
\text { conhecimentos } \\
\text { e experiências }\end{array}$ & Relato 10 & $\begin{array}{l}\text { Entrevistado A2: Tecnologias a gente sempre faz as consultas. Desde o início a gente } \\
\text { tenta identificar pontos de melhoria dentro de artigos do mundo acadêmico. A } \\
\text { gente tá sempre tentando identificar isso com fornecedores também, que são muito } \\
\text { importantes. }\end{array}$ \\
\hline
\end{tabular}

Entrevistado A1: A gente usa uma wiki interna, tem email colaborativo, [...] tem repositório de dados. [...] uma série de ferramentas [para] estar registrando o conhecimento e mantendo o conhecimento internamente.

\begin{tabular}{|c|c|c|}
\hline & & $\begin{array}{l}\text { positório de dados. [...] uma série de ferramentas [para] estar registrando o conheci- } \\
\text { mento e mantendo o conhecimento internamente. }\end{array}$ \\
\hline \multirow[t]{2}{*}{$\begin{array}{l}\text { Licenciamento e } \\
\text { comercialização } \\
\text { de tecnologias }\end{array}$} & Relato 11 & $\begin{array}{c}\text { Entrevistado A2: E essa tecnologia [...] nós vamos deixar com que os outros explorem } \\
\text { pra nós. Mas, em troca então vocês paguem o que é devido nesse mercado [...] Esse } \\
\text { é o grande desafio: um milhão, dois milhões, três, quatro, dez, quanto vale essa fatia } \\
\text { de mercado? }\end{array}$ \\
\hline & Relato 12 & $\begin{array}{c}\text { Entrevistado A2: Pra transferência de tecnologia é muito burocrático [...] Nós já tive- } \\
\text { mos uma experiência de uma tentativa de início de transferência de uma tecnologia } \\
\text { com uma empresa grande, [...] e não deu certo por causa dos trâmites burocráticos } \\
\text { entre instituições. }\end{array}$ \\
\hline
\end{tabular}

Entrevistado A1: Quase todas as empresas existentes aqui [...] tem professor envolvido. Então nesse momento eles falaram que não poderia haver. [...] Esse ponto cria um estrangulamento muito grande no processo. [...] Mata o movimento de inovação.

Entrevistado B1: [...] um cliente nosso que é uma instituição pública e o processo de aquisição do nosso equipamento levou quase um ano de processo licitatório, envio de documentos foi muito moroso, foi bem difícil. [...] empresas particulares elas tem uma desenvoltura maior, pelo fato de não terem tanta burocracia.

Entrevistado A1: Nós tivemos [...] um contrato de licenciamento que ficou durante dois anos no jurídico da universidade, pra no final a Universidade falar que por causa da lei de moralidade, o professor não poderia ser parte da empresa, sendo que, a [...] lei de inovação isso é preconizado.

Relato 13 Entrevistada B2: É pela transferência mesmo de tecnologia [...] os ganhos são estabelecidos nos contratos, na forma em que essa tecnologia é transferida. [...] patente é comercializada na íntegra ou é um licenciamento.

Relato 14 Entrevistada B1: Pra transferência de tecnologia é muito burocrático. [...] nós já tivemos uma experiência de uma tentativa de início de transferência de uma tecnologia com uma empresa grande, [...] e não deu certo por causa dos trâmites burocráticos entre instituições.

Fonte: Dados da pesquisa. 
Em geral, como pode ser observado na subcategoria Necessidades Específicas, recorrese a fontes externas quando se trata de uma competência que sai das competências centrais das startups, semelhante ao que colocam Cowan, Jonard e Zimmermann (2007). Muitas vezes as fontes externas acabam por nortear a trajetória de inovação da startup, conforme Relato 6 . A Startup A apresenta uma característica particular. Observa-se que para alcançar novas tecnologias busca suprir suas necessidades específicas que não são supridas internamente. Especificamente, são as necessidades identificadas junto aos clientes que levam à procura por fontes externas. No Relato 7 observa-se que o contato é feito, e havendo interesse das partes, inicia-se o processo de estabelecimento da parceria. As necessidades específicas (subcategoria) sendo limitante ao crescimento da startup, potencializa a busca por fontes externas de conhecimento e a inovação aberta, ao ponto que, ela utiliza deste meios para superar as carências internas.

Na subcategoria Competências complementares foi possível observar que as startups não possuem interesse em encontrar parceiros quando já possui a competência que precisa para o processo de inovação. Então, como pode ser observado no Relato 8, principalmente quando se verifica a necessidade de competências complementares é que fontes externas são procuradas, evitando custos de desenvolvimento de infraestrutura e de pessoal que seriam necessários caso a empresa optasse pelo desenvolvimento interno.

As atividades inerentes à inovação aberta, nesse contexto, tem caráter interativo e sistêmico, o que implica que a aprendizagem ocorre por interação - o que consiste em um fator potencializador para o uso da inovação aberta (buscam fontes externas quando as internas não complementam). Como pode ser observado, as startups procuram tornar a inovação um resultado de interações de modo colaborativo (mesmo com diversas restrições) de vários atores com competências e experiências distintas. No entanto, mesmo sendo essas competências diferentes, elas se complementam, e dessa forma, as startups conseguem se inserir em processos de inovação aberta marcados pela busca de fontes de conhecimentos e tecnologias.

Apesar desse não ser o principal motivo para as empresas se aproximarem das fontes externas de tecnologia, os menores custos têm sua contribuição para a decisão de não se desenvolver internamente essas competências. Dessa forma, mesmo em contexto diferente, os relatos corroboram os resultados alcançados por Benedetti e Torkomian (2013), as empresas procuram fontes externas para aproveitar a redução de custos aliada a diminuição de tempo gasto na produção. Como verificado nos relatos e em consonância com a literatura não é exclusivamente a falta de uma determinada competência que leva a empresa a procurar fontes externas (Broring \& Herzog, 2008; Slowinski et al., 2009).

Constatou-se, na subcategoria Compartilhamento de conhecimentos e experiências, que a Startup A, apesar de não compartilhar seus conhecimentos com o meio externo, se preocupa bastante em absorver conhecimento de fontes externas, sejam as fontes de caráter científico ou mercadológico. Além de manter uma base de dados e informações em intranet, que é a plataforma de gestão do conhecimento com possibilidade de acesso de todos os membros da empresa (Relato 10).

Todavia, isso se constitui um fator restritivo a inovação aberta, pois impedem que todas as possibilidades de geração de conhecimento estejam disponíveis e acessíveis aos pesquisadores, levando-os a interagir com outras áreas para que haja recombinação dos conhecimentos. Outra questão restritiva ao uso da inovação aberta é a desconfiança para compartilhar conhecimento 
e experiência. Chesbrough (2003) esclarece que no processo de inovação aberta os fluxos não são apenas na direção da empresa, e, sim, multidirecionais. Como foi observado, as trocas que ocorrem entre empresas podem ser vistas como uma ameaça que pode diminuir a competitividade - posicionamento inverso ao do modelo de inovação aberta. Assim, como pontuam Calligaris e Torkomian (2003) e Broring e Herzog (2008) mesmo entre concorrentes, essas ações devem ser vistas como ações estratégicas para aumento da competitividade e não uma ameaça.

A transferência ou licenciamento de tecnologias com fontes externas constituem práticas fundamentais ao processo de inovação aberta (Chesbrough, 2006). Como pode ser observada na subcategoria Licenciamento e comercialização de tecnologias, pela análise documental, a Startup A se caracterizou pelo interesse em ceder uma tecnologia não utilizada internamente para terceiros, entretanto, como pontuou o Entrevistado A1, encontraram barreiras na legislação. Finalmente observou-se que a questão da propriedade intelectual aumenta a complexidade da adoção do modelo aberto de inovação, pois interesses e objetivos distintos podem gerar dificuldades para o estabelecimento de acordos entre os parceiros. Aqui, novamente questões relacionadas à legislação e a burocratização destes processos aparecem como fatores restritivos.

Conforme pode ser verificado nessa discussão, a busca por fontes externas da Startup A está centrada no fluxo de entrada de novos conhecimentos e tecnologias, com a intenção de se estabelecer um fluxo de saída de tecnologias não aplicadas aos seus negócios. Todavia, observou-se que a adoção dessa prática proposta no modelo teórico ainda faz parte de um tradeoff que ocorre entre a exploração ou a transferência da tecnologia - que pode descaracterizar o processo de inovação aberta (Chesbrough, 2003; 2006). Analisando os documentos da Startup $B$, verificou-se que ela não pretende usar suas patentes apenas para garantir a exclusividade para a exploração, mas posteriormente pretende obter ganhos por meio de licenciamento. Ou seja, objetiva-se usar as patentes de maneira estratégica de geração de valor, corroborando com as conceituações de Chesbrough (2003) - fato que também pode ser verificado pelo Relato 13. Encontrou-se neste tópico também uma desvantagem (fator restritivo) em se estabelecer parcerias com outras instituições de ensino e pesquisa. Conforme a Entrevistada B1 no Relato 14, os entraves burocráticos, as leis que regem a propriedade intelectual e a inovação (Lei n. 10.973, 2004) e o princípio da legalidade da Administração Pública (Constituição da República Federativa do Brasil, 1988/2001), prejudicam as práticas de transferência de tecnologia.

Diferentemente, na Empresa B verificou-se uma tendência de disponibilizar as tecnologias geradas internamente para outras empresas, nesse sentido, há retornos financeiros através dos processos de transferência de tecnologia, o que resulta em uma grande aderência ao modelo de inovação aberta proposto na literatura. Principalmente, nessa subcategoria a Empresa $B$ se diferencia da Empresa A.

Adiante, a preocupação do governo brasileiro em aproximar os pesquisadores das universidades com as empresas para a geração de inovações e aumento da competitividade do país no cenário internacional, ressaltado nos estudos de Calligaris e Torkomian (2003), pôde ser identificada neste estudo em questão através de diversos relatos. Sem dúvida as parcerias são essenciais para o desenvolvimento e crescimento das startups analisadas, em especial, a parceria com a universidade e a adoção do modelo de inovação aberta. Nesse sentido, a universidade desempenha papel central até mesmo para a sobrevivência das empresas analisadas. Porém, de acordo com os mesmos relatos, ainda a arestas a serem aparadas na legislação (e nas relações 
empresa-governo-universidade), sendo esse, um dos maiores fatores restritivos para o processo de inovação aberta nessas startups.

\section{CONCLUSÕES E RECOMENDAÇÕES}

As pesquisas sobre inovação aberta apresentaram crescimento significativo nos últimos anos, entretanto, mesmo com os avanços, encontram-se na literatura diversas lacunas de pesquisa no que tange a inovação aberta em startups, pequenas e médias empresas. No intuito de preencher uma dessas lacunas, este trabalho, objetivou descrever e analisar os desafios da inovação aberta, em startups de base tecnológica, através dos fatores potencializadores e restritivos presentes na busca por fontes externas de conhecimento. A pesquisa foi realizada em duas startups.

De maneira geral, foi possível verificar que a universidade é um ator central (potencializador) tanto para o surgimento, quanto no processo de inovação aberta e contribui em termos de estrutura física, transferência de credibilidade, oferecendo mão de obra especializada e, também, por meio da qualificação dos profissionais e pesquisadores (na maioria dos casos, bolsistas de agências de fomento ou professores). Assim, a aproximação com a universidade para as startups é um ponto crucial para permanência no mercado. Além da ajuda em termos de estrutura física a universidade facilita o acesso aos editais de financiamento o que contribui para a P\&D. Outra vantagem desse relacionamento é a fato de se ter a marca da empresa ligada a universidade transmitindo confiabilidade. Logo, a universidade é o principal fator potencializador encontrado na pesquisa. Diferentemente do encontrado nesta pesquisa, para as grandes empresas a universidade é apenas um meio para encontrar soluções para os problemas, onde se inicia então, um processo de cooperação (Benedetti \& Torkomian, 2013).

Apesar das vantagens do relacionamento com a universidade e com incubadora de empresas que oferecer apoio estrutural favorável à aplicação dos resultados de suas pesquisas em inovações do setor produtivo, existem alguns fatores que limitam a busca por fontes externas pelas startups (fatores restritivos). O primeiro é o fato das patentes estarem vinculadas a professores universitários, o que diminui as opções para as empresas trabalharem com transferência de patentes, desenvolverem novas tecnologias ou adquiri-las prontas para as utilizarem em seus negócios. Tal fato é resultante dos processos burocráticos que envolvem a transferência de tecnologia e a compra e venda dos produtos originários das patentes. Embora a Lei de Inovação incentive à pesquisa científica e tecnológica no ambiente produtivo, para as startups analisadas existe um choque com a Lei de Licitação (Lei n. 8.666, 1993). A lei da inovação preconiza a participação de professores e pesquisadores nos projetos de invenção de tecnologia e P\&D, porém, por se tratar de pequenas empresas fundadas por professores, esbarram no princípio da moralidade da Constituição Federal de 1988 (Constituição da República Federativa do Brasil, 1988/2001). Uma vez que, enquanto servidores da administração pública não podem participar de processos licitatórios e, nem tão pouco, de contratos de compra e venda seja diretamente ou indiretamente (Lei n. 8.666, 1993). Conforme objetivo deste artigo este fenômeno se torna o principal fator restritivo da inovação aberta das startups de base tecnológica presente na busca por fontes externas de conhecimento

A questão da propriedade intelectual nas startups analisadas é um ponto central também na estratégia de inovação, assim como nas grandes empresas segundo Benedetti e Torkomian 
(2013). Porém, no presente contexto, especialmente quando se usa o modelo aberto, existe uma diferença crucial para um melhor andamento desse tipo de inovação: nas grandes empresas a preocupação com a apropriabilidade das patentes é justificada pelos ganhos provenientes do período em que as empresas podem explorar e ampliar o uso de suas inovações (Benedetti \& Torkomian, 2013), já as startups enfrentam dificuldades em comercializar e transferir suas patentes e os produtos originários dela. Portanto, restringe a adoção de um modelo aberto de inovação.

Concluí-se também que para as startups analisadas, o envolvimento com fontes externas concentra-se no sentido de entrada de conhecimentos e novas tecnologias, deixando de lado o sentido de saída de novas tecnologias que não se alinham aos negócios, mas que teriam potencial de geração de receita (e agregação de valor) por meio da exploração por terceiros. Este fator restritivo se relaciona diretamente aos aspectos culturais das startups (Ades et al., 2013). Tal fato indica uma realidade que não contempla plenamente o modelo teórico da inovação aberta em decorrência de especificidades das startups e de limitações estruturais e legais. Mesmo com a universidade potencializando as práticas de inovação aberta.

Por fim, a metodologia utilizada foi estudo de casos múltiplos, assim, faz-se necessário considerar que os resultados apresentados, suas interpretações e considerações, ficaram sujeitos a limitações. Apesar da riqueza em profundidade que essa metodologia possibilita, fica limitada a sua extensão, o que é possível ao se utilizar outros métodos aplicados a amostras maiores e estatisticamente significativas. Em destaque, as startups estudadas estão incubadas em uma mesma universidade. Portanto, os fatores potencializadores e restritivos encontrados se referem a esta realidade e não se têm dados se eles são encontrados em outras. Outra limitação se refere a carência de uma abordagem teórica mais aprofundada sobre as legislações referentes aos incentivos e entraves a inovação em startups e pequenas empresas, já que esta questão foi resultante do trabalho de campo.

Nesse sentido, sugere-se para pesquisas futuras: i) estudar as problemáticas da transferência de tecnologia em startups e pequenas empresas; ii) aprofundar as discussões sobre a legislação, as políticas de incentivo e os impactos nas práticas de inovação aberta nessas empresas; iii) analisar a importância da inovação aberta na relação entre startups e universidades, em especial, no que se refere a questão da propriedade intelectual; iv) estudar a formação de redes de inovação aberta e as vantagens competitivas geradas em arranjos que estejam envolvidas startups; e v) pesquisar modelos de negócios coerentes com a inovação aberta nessas organizações. Essas e outras pesquisas podem ampliar os debates teóricos e 0 campo de pesquisas empíricas sobre inovação aberta em startups. 


\section{REFERÊNCIAS BIBLIOGRÁFICAS}

Abouzeedan, A., \& Hedner, T. (2012). Organization structure theories and open innovation Paradigm, World Journal of Science, Technology and Sustainable Development, 9(1), 6-27.

Ades, C., Figlioli, A., Sbragia, R., Porto, G., Plonski, G. A., \& Celad, K. (2013). Implementing Open Innovation: The Case of Natura, IBM and Siemens. International Journal of Innovation Management, 8(spl), 12-25.

Alberone, M., Carvalho, R., \& Kircove, B. (2012). Sua ideia ainda não vale nada: 0 guia prático para começar a validar seu negócio. Rio de Janeiro.

Ballon, P., \& Hawkins, R. (2009). Standardization and business models for platform competition: the case of Mobile television, International Journal of IT Standards and Standardization Research, 7(1), 1-12.

Bardin, L. (2004). Análise de conteúdo. Edições 70: Lisboa.

Benedetti, M. H. \& Torkomian, A. L. V. (2009, setembro). Cooperação Universidade-Empresa: uma relação direcionada à Inovação Aberta. Anais do Encontro da Nacional de Pós-Graduação e Pesquisa em Administração, São Paulo, SP, Brasil, 33.

Benedetti, M. H. \& Torkomian, A. L. V. (2013, setembro). A Contribuição de fontes externas no processo de inovação das empresas. Anais do Encontro da Nacional de Pós-Graduação e Pesquisa em Administração, Rio de Janeiro, RJ, Brasil, 37.

Blank, S., \& Dorf, B. (2012). The Startup Owner's Manual: The Step-By-Step Guide for Building a Great Company. K\&S Ranch Editora, California.

Brigidi, G. M. (2009). Criação de Conhecimento em Empresas Start-up de Alta Tecnologia. 2009. 179 fl. Dissertação (Programa de Pós-Graduação em Administração da Universidade Federal do Rio Grande do Sul) - Universidade Federal do Rio Grande do Sul, Porto Alegre.

Broring, S., \& Herzog, P. (2008). Organising new business development: open innovation at Degussa, European Journal of Innovation Management, 11(3), 330-348.

Bueno, B., \& Balestrin, A. (2012). Inovação colaborativa: uma abordagem aberta no desenvolvimento de novos produtos. Revista de Administração de Empresas, 52(5), 517-530.

Calligaris, A. B., \& Torkomian, A. L. V. (2003). Benefícios do desenvolvimento de projetos de inovação tecnológica, Revista Produção, 13(2), 21-32. 
Chaston, I., \& Scott, G. J. (2012). Entrepreneurship and open innovation in an emerging economy, Management Decision, 50(7), 1161-1177.

Chesbrough, H. (2003). Open innovation: the new imperative for creating and profiting from technology. Harvard Business School Press: Boston.

Chesbrough, H. W., \& Vanhaverbeke, W. J. (2006). Open innovation: researching a new paradigm. New York: Oxford University Press.

Chesbrough, H., \& Crowther, A. K. (2006). Beyond high tech: early adopters of open innovation in other industries, R\&D Management, 36(3), 229-36.

Chesbrough, H., \& Schwartz, K. (2007). Innovating business models with co-development partnerships, Research Technology Management, 50(1), 55-59.

Cohen, W. M., \& Levinthal, D. A. (1990). Absorptive Capacity: a new perspective on learning and innovation, Administrative Science Quarterly, 35(1), 128-152.

Constituição da República Federativa do Brasil de 1988. (2001). [Coleção Saraiva de Legislação]. (21a ed.). São Paulo: Saraiva.

Costa, J. C., \& Maçada, A. C. G. (2011, setembro). Inovação aberta em um processo de terceirização de ti: análise de um caso de inovação de processo no setor automotivo. Anais do Encontro da Nacional de Pós-Graduação e Pesquisa em Administração, Rio de Janeiro, RJ, Brasil, 35.

Cowan, R., Jonard, N., \& Zimmermann, J-B. (2007). Bilateral collaboration and the emergence of innovation networks, Management Science, 53(7), 1051-1067.

Dosi, G. (1988). Sources, procedures and microeconomic effects of innovation. Journal of Economic Literature, 26(3), 1120-1171.

Enkel, E., Gassmann, O., \& Chesbrough, H. (2009). Open R\&D and open innovation: exploring the phenomenon, R\&D Management, 39(4), 311-16.

Etzkowitz, H., \& Leydesdorff, L. (1999). The future location of research and technology transfer, Journal of Technology Transfer, 24(2-3), 111-123.

Financiadora de Estudos e Projetos (Finep). (2012). Glossário. Disponível em: <http://www. finep.gov.br/o_que_e_a_finep/conceitos_ct.asp>. Acessado 13 de out. de 2014.

Freeman, C. (1991). Networks of innovators: a synthesis of research issues. Research Policy, 20(5), 499-514. 
Gassmann, O., Daiber, M., \& Enkel, E. (2011). The role of intermediaries in cross-industry innovation processes, R\&D Management, 41(5), 457-69.

Godoy, A. S. (1995). Introdução à pesquisa qualitativa e suas possibilidades. Revista de Administração de Empresas, 35(2), 57-63.

Hayton, J. C. (2002). The effect of intellectual capital on entrepreneurial orientation in high technology new ventures. 2002. 187 fl. Dissertation (Doutorado em Administração) - J. Mack Robinson College of Business, Georgia State University, Atlanta.

Hossain, M. (2013). Open innovation: so far and a way forward world. Journal of Science, Technology and Sustainable Development, 10(1), 30-41.

Huizingh, E. K. R. E. (2011). Open innovation: state of the art and future perspectives. Technovation, 31(1), 2-9.

Jong, J. P. J., \& Marsili, O. (2006). The fruit flies of innovations: a taxonomy of innovative small firms, Research Policy, 35(2), 213-29.

Kim, H., \& Park, Y. (2010). The effects of open innovation activity on performance of SMEs: the case of Korea, International Journal of Technology Management, 52(3-4), 236-256.

Laursen, K., \& Salter, A. J. (2004). Searching high and low: what type of firms use universities as a source of innovation? Research Policy, 33(8), 1201-1215.

Lee, S., Park, G., Yoon, B., \& Park, J. (2010). Open innovation in SMEs - an intermediated network model, Research Policy, 39(2), 290-300.

Lei n. 10.973, de 2 de dezembro de 2004 (2004). Dispõe sobre incentivos à inovação e à pesquisa científica e tecnológica no ambiente produtivo e dá outras providências. Diário Oficial da União. Brasília, DF.

Lei n. 8.666, de 21 de junho de 1993 (1993). Regulamenta o art. 37, inciso XXI, da Constituição Federal, institui normas para licitações e contratos da Administração Pública e dá outras providências. Diário Oficial da União. Brasília, DF.

Lichtenthaler, U. (2008). Open innovation in practice: an analysis of strategic approaches to technology transactions, Transactions on Engineering Management, 55(1), 148-57.

Lorenzoni, G., \& Baden-Fuller, C. (1995). Creating a strategic center to manage a web of partners. California Management Review, 37(3), 146-163. 
Lussier, R. N. (1995). A non-financial business success versus failure prediction model for young firms. Journal of Small Business Management, 33(1), 8-20.

Massa, S., \& Testa, S. (2008). Innovation and SMEs: misaligned perspectives and goals among entrepreneurs, academics, and policy makers, Technovation, 28(7), 393-407.

Minshall, T., Mortara, L., Valli, R., \& Probert, D. (2010). Making 'asymmetric' partnerships Work, Research-Technology Management, 53(3), 53-63.

Munsch, K. (2009). Open model innovation, Research Technology Management, 52(3), 48-52.

Narula, R. (2004). R\&D collaboration by SMEs: new opportunities and limitations in the face of globalisation. Technovation, 25, 153-161.

Neyens, I., Faems, D., \& Sels, L. (2010). The impact of continuous and discontinuous alliance strategies on startup innovation performance. International Journal of Technology Management, 52(3-4), 392-410.

Parida, V., Westerberg, M., \& Frishammar, J. (2012). Inbound open innovation activities in hightech SMEs: the impact on innovation performance, Journal of Small Business Management, 50(2), 283-309.

Perkmann, M., \& Walsh, K. (2007). University-industry relationships and open innovation: Towards a research agenda, International Journal of Management Reviews, 9(4), 259-280.

Pinho, M.; Côrtes, M. R.; Fernandes, A. C. (2002). A fragilidade das empresas de base tecnológica em economias periféricas: uma interpretação baseada na experiência brasileira. Ensaios FEE, Porto Alegre, 23(1), 135-162.

Pitassi, C. (2012). A virtualidade nas estratégias de inovação aberta: proposta de articulação conceitual. Revista de Administração Pública, 46 (2), 619-641.

Richardson, R. J. (1999). Pesquisa Social: métodos e técnicas. São Paulo: Atlas.

Salim, C. S., Hochman, N., Ramal, A. C., \& Ramal, S. A. Construindo Plano de Negócios. Rio de Janeiro: Campus, 2005.

Sandulli F. D., \& Chesbrough, H. (2009). Open business models: las dos caras de los modelos de negocioabiertos, Universia Business Review, 22(22), 12-39.

Savitskaya, I., Salmi, S., \&Torkkell, M. (2010). Barriers to open innovation: case China. Journal of Technology Management \& Innovation, 5(4), 10-21. 
Serviço de Apoio às Micro e Pequenas Empresas. (Sebrae). (2012). O que é uma startup? Disponível em: <http://www.sebrae.com.br/sites/PortalSebrae/sebraeaz/O-que-\%C3\%A9-umastartup\%3F>. Acessado 13 de out. de 2014.

Slowinski, G., Hummel, E., Gupta, A., \& Gilmont, E. R. (2009). Effective practices for sourcing innovation, Research Technology Management, 52(1), 27-34.

Souza, F. A. \& Mello, C. H. P. (2013, outubro). Diagnóstico das práticas de inovação aberta aplicadas por empresas graduadas de tecnologia. Anais do Encontro Nacional de Engenharia de Produção, 2013, Salvador, BA, Brasil, 29.

Spithoven, A., Vanhaverbeke, W., \& Roijakkers, N. (2013). Open innovation practices in SMEs and large enterprises, Small Business Economics, 41(3), 537-562.

Suh, Y., \& Kim, M. (2012). Effects of SMEs' collaboration on service R\&D in open innovation, Innovation: Management, Policy \& Practice, 14(3), 350-64.

Triviños, A. N. S. (1987). Introdução à pesquisa em ciências sociais: a pesquisa qualitativa em educação. São Paulo: Atlas.

Van de Vrande, V., Jong, J. P. J., Vanhaverbeke, W., \& Rochemont, M. (2009). Open innovation in SMEs: trends, motives and management challenges, Technovation, 29(6-7), 423-37.

Vergara, S. C. (2000). Projetos e relatórios de pesquisa em Administração. Atlas: São Paulo.

Vieira, K. C., Alcântara, V. C., \& Bermejo, P. H. S. (2014). Use of external sources of knowledge for innovation in technology-based SME's. Business \& Management Review, 3( 9), 12-24.

Vrgovic, P., Glassman, B., Walton, B., \& Vidicki, P. (2012). Open innovation for SMEs in developing countries: an intermediated communication network model for collaboration beyond obstacles, Innovation: Management, Policy e Practice, 14(3), 587-614.

Waguespack, D. M., \& Fleming, L. (2009). Scanning the Commons? evidence on the benefits to startups participating in open standards development. Management Science, 55(2), 210-223.

Witzeman, S., Slowinski, G., Dirkx, R., Gollob, L., Tao, J., Ward, S., \& Miraglia, S. (2006). Harnessing external technology for innovation, Research Technology Management, 49(3), 19-27.

Yin, R. K. (1984). Case study research: design and methods. Sage: London.

Zeng, S. X., Xie, X. M., \& Tam, C. M. (2010). Relationship between cooperation networks and innovation performance of SMEs, Technovation, 30(3), 181-94. 